\title{
Ohmic Heating Technology - A Review
}

\author{
M. G. Anjaly* and Ann Annie Shaju \\ Department of Processing and Food Engineering, Kerala Agricultural University (KAU), \\ Kerala, India \\ *Corresponding author
}

\section{Keywords}

Liquid eggs, industrial applications, resistance, equipment

Article Info

Received: 05 November 2021 Accepted: 30 November 2021 Available Online: 10 December 2021

\section{A B S T R A C T}

Ohmic heating is a novel technology for food processing. This review paper summarizes there search progress and application in Ohmic heating technology used in food processing. Ohmic heating is an electrical resistance heating method for the heat treatment of food products. When electric current passes through the food, the food heats up because of its internal electrical resistance. In this process heating rate depends upon the electrical conductivity and field strength. By this method a product under goes a minimum structural damage, retain its nutritional value. This technique gives excellent processed quality products in minimum operating time.

\section{Introduction}

In 1827, Georg Ohm, was the first to outline which is known as Ohm's law but recognition of the thermal effects of electricity within a conductor was the first elucidated by James Prescott Joule in 1840. The technology was once again revived in the 1980 and some industrial applications have resulted, including pasteurization of liquid eggs and processing of fruit products, among others.

Ohmic heating concept was used in the early 20th century where electric pasteurization of milk and other food materials were achieved by pumping the fluid between plates with a voltage difference between them (1). Ohmic heating is a resistance heating technique for liquids foods (2). It consists of equipment for passing alternative current through the fluid between electrodes (3).

Ohmic heating is used in a wide range of applications such as pasteurization, sterilization, preheating, blanching (4). This is one of the excellent and efficient alternative methods of heating; this technique shows much promise especially in food industry over the last few decades, because there is an increasing shift from batch thermal operation 
towards continuous high temperature and short time processing of foods (5).

Fundamentals and critical parameters of ohmic heating

An Ohmic heater is an electrical heating device that uses a liquid's own electrical resistance to generate the heat (6). Ohmic heating works on the principle of Ohm's law of electricity. The passage of electric current through an electricity conductive food material obeys Ohm's law and heat is generated due to electrical resistance of food.

$\mathrm{V} \propto \mathrm{I}$

$\mathrm{V}=\mathrm{IR}$

Where $\mathrm{V}=$ Voltage (volt), $\mathrm{I}=$ Current (ampere), $\mathrm{R}=$ Resistance $(\mathrm{Ohm})$.

\section{Effects of Ohmic Heating Physiochemical Property of Foods}

Pereira et al., (7) studied the effect of ohmic and conventional heat processing of different food Products on their chemical and physical parameters. Parameters such as $\mathrm{pH}$, total solid, ash, titratable acidity, ascorbic acid, total sugar, total fatty acids, total phenolic compounds and anthocyanins content were determined before and after ohmic heating and conventional pasteurization techniques. Goat milk samples were treated by ohmic heating technology the $\mathrm{pH}$ was 6.58 and total fatty acid was $86.5 \%$. Ohmic treated samples show a lower content of lactic acid $0.13 \%$. Chemical analysis of food products indicated similar chemical properties treated by both ohmic heating treatment and conventional treatment.

Samaranayake (8) determined the minimization of electrochemical reactions during ohmic heating. Ohmic heating is capable of reducing the electrochemical reaction of stainless steel, titanium and platinized- titanium electrodes compared with conventional $60 \mathrm{~Hz}$ ohmic heating. In general, except at the highest frequency low duty-cycle heating, pulsed ohmic heating was less successful in suppressing the electrochemical reaction of graphite electrodes compared with conventional ohmic heating. Ohmic heating provides its best result for graphite electrodes. It is suitable for minimization of electrochemical reaction.

Viscosity of milk decreased with increasing temperature because increase in temperature leads to lower milk fatty blocs which are responsible for the high viscosity of milk. The relationships between viscosity and temperature were first-order equations for all electrical fields. Milk density was reduced by increasing milk temperature. This reduction was started after the rising of milk temperature above $40^{\circ} \mathrm{C}$ (9).

\section{Effect of Ohmic Heating on Microbial Activity}

Kumar et al., (10) studied the inactivation effects of ohmic and conventional heating on total plate count, molds and yeast, E. coli, coliforms and salmonella in buffalo milk under identical temperature conditions. Resulted the microbial counts from ohmic heating were lower than conventional heated milk. Salmonella were completely killed by ohmic heating treatment. Microbial destruction was higher in ohmic heat treated samples as compared to conventional heattreated samples. Soft Paneer was obtainedby ohmic treated milk samples and sensory pane list of this soft paneer was superior to Paneer obtained from traditional method.

Kim et al., (11) investigated the lethality within foods particles under going $5 \mathrm{~kW}$ ohmic heating system used microbiological and chemical marker measurements. Meat ball 
contains spores of B. stearo thermophilus and precursors of chemical markers were thermally processed in the solution of starch with 30 to $40 \%$ solids content. Higher lethality was observed, microbiologically and chemically, at the centre of the meat balls rather than near the surface. They concluded that ohmic heating had a high potential for providing high quality of food products, shelf stable foods that were not achieved by conventional thermal processing.

\section{Electroporation effect during ohmic heating}

Lebovka(12) studied the effect of temperature on electroporation of plant tissues during the pulsed electric field or alternative current. He was determined the effectiveness of the electroporation effect in plant tissues damage for potatoes tissues in the range of electric field strengths $40-500 \mathrm{~V} / \mathrm{cm}$, at temperatures $22^{\circ} \mathrm{C}$ and $49^{\circ} \mathrm{C}$ in pulsed electric field treatment. Ohmic heating of potato and apple tissues were evidence of the importance of the electroporation mechanism of tissues damage at moderate electric fields under $100 \mathrm{~V} / \mathrm{cm}$ and effectiveness of this mechanism increased with temperature increased. He observed the importance of the electroporation mechanism in plant tissues damage was induced by ohmic heating which is controlled by temperature induced changed in the cell membrane structure.

Cho et al., (13), (USA-FDA, 2000) investigated the incidence of electric field in the fermentative Process may cause membrane electroporation provoking faster and efficient nutrient transport to the interior of the cell, thus reducing the lag phase of the fermentation. Ohmic heating has demonstrated to cause productivity decrease. This decrease may also be related to the electroporation effect which possibly allows the transport of metabolites to the interior of the cell and consequently inhibits the fermentative process. The critical parameters of ohmic heating are electrical conductivity of food, frequency and form of wave, particle size, heat capacity and viscosity.

\section{Electrical conductivity}

Electrical conductivity is the main parameter in ohmic heating. Biological materials are one of the largest classes of poor heat conductors. The heating effect depends on the moisture content and concentration of ions in it. For most food stuffs, the electrical conductivity varies mainly depending on the temperature and voltage gradients used. For purely liquid foods, the electrical conductivity increases linearly with temperature but overall falls as the concentration of pulp in it increases. Electrical conductivity of food products should be greater than $0.05 \mathrm{~S} / \mathrm{m}$ for good behaviour of ohmic heating. Examples: - milk desserts, yoghurts, eggs, fruit juices, condiments, gelatin, wine and hydrocolloids, etc. The orange juice concentrates having 0.20-0.60 mass fraction were ohmic heated by using five different voltage gradients (20-60 $\mathrm{V} / \mathrm{cm})$. The electrical conductivity values were in the range of $0.15-1.25 \mathrm{~S} / \mathrm{cm}$ showing an increasing trend with decreasing concentration (14).

\section{Frequency and Form of wave}

The common frequencies employed for ohmic heating of foods are $50 \mathrm{~Hz}$ and $60 \mathrm{~Hz}$. Frequency and waveform of applied voltage affects the electrical conductivity values and the process of heating the samples. Some studies (15) also suggested that with low frequency electrical conductivity values were high and further electrical conductivity of turnip tissue used in the experiment was significantly higher for sine and saw tooth waves as compared to the square waves at 4 Hz. The lowest effective frequency would be a worth while subject for further research, since 
improved mass transfer has been reported for frequencies as low as $4 \mathrm{~Hz}$. Altering the frequency and wave form of alternating current during ohmic heating has been shown to influence the heat and mass transfer properties of foods.

\section{Product size, heat capacity and viscosity}

Smaller particles like emulsions, colloids (which were less than $5 \mathrm{~mm}$ ), the effect of orientation on the conductivity can be ignored but for larger particles (15-25 $\mathrm{mm})$, orientation relative to the electrical field has a significant influence on electrical properties as well as the relative heating rates of the phases(16). When solid particles suspended in a fluid medium both have similar electrical conductivities, the component among them having lower heat capacity will have the tendency to heat faster. Food shaving high densities and high specific heat values are conducive to slower heating (17). Fluid viscosity also influences ohmic heating; higher viscosity fluids tend to result in faster ohmic heating than lower viscosity fluids.

\section{Applications of ohmic heating}

\section{Thawing}

To increase the shelf life of meat products frozen storage is important. Meat thawing by ohmic heating is fast and less weight loss was observed in the sample. The fast thawing process gives better quality of meat products because of decrease unwanted microbial activity during thawing (18).

\section{Meat ball cooking and poultry products}

Ohmic cooking procedure was found to be safe in terms of PAH formation and mutagenic activity. Sensory evaluation showed that overall acceptance of the semi cooked meat ball samples was good. High cooking yield, moisture retention and fat retention values in samples were obtained with ohmic cooking (19). The quality of the ohmic heated chicken breast samples was similar or superior to that of the retort- heated samples based on the measurement of water content and glutamic acid in the treated sample. The sample quality did not deteriorate or degrade during storage (20).

\section{Extraction}

Model of ohmic heating showed good performance when used for ohmic and enzyme assisted aqueous extraction of rape seed oil(21). Improve the extraction of soy milk from soybeans by ohmic heating (22). Diffusion of beet dye from beetroot into a carrier fluid was increased in ohmic heating and the amount of dye extracted was proportional to the electrical field strength used (23).

\section{Blanching}

Blanching by ohmic heating permits the effective damage of food product's cells by combination of thermal and electrical effects. By ohmic heating osmotic dehydration of strawberries enhances the water and sugar transfer (24). Ohmic heating is popular due to its volumetric heating rates, rapid process and the enhancement of mass transfer even at relatively low temperatures.

\section{Pasteurization}

Leizerson and Shimoni, (25) measured higher concentration of ohmic heated pasteurized orange juice during storage and the storage period was 105 days, resulted the particle size was lower in ohmic heated orange juice also prevented the growth of microorganism, and the shelf life of ohmic treated orange juice was $>100$ days. It was second time longer than these of conventionally pasteurized juice. 


\section{Expression}

Enhancement of carrot juice recovery using 2stage pressing with ohmic heating. Mathematical analysis for multi stage pressing applied to second stage expression process. The total carrot juice recovery increased in the duration of first pressing. Maximum enhancement in carrot juice recovery in second stage expression with ohmic heating over control was $13.76 \%$, resulted that the ohmic heating did not cause much change in the colour of carrot juice. In the first pressing, maximum carrot juice recovery was $98.9 \%$ in 2.72 minutes, in the second pressing ohmic heating temperature was $65.60{ }^{\circ} \mathrm{C}$; voltage gradient was $15 \mathrm{~V} / \mathrm{cm}$ for the time duration of 10 minutes (26).

\section{Stabilization of raw rice bran}

$10 \mathrm{Kg}$ rice bran was hydrated and heated byflow of electric current through ohmic heating system. The treated sample was observed to be stable even after 75 days of storage in the comparison of raw rice bran sample. The free fatty acid (FFA) percent in ohmic heated rice bran was observed to be $4.77 \%$ after 75 days of storage whereas it was $41.84 \%$ in case of rawrice bran. The FFA concentration of the ohmic heated samples increased very slowly in comparison to raw rice bran samples during 75 days of storage (27).

\section{Drying}

In the vacuum dryer ohmic heated sample take less time for drying compared to raw samples. The maximum reduction of time was $24 \%$ (28). Ohmic treatment helps in a significant decreasein time required for vacuum drying and positively effects the economic and product quality. Ohmic heating is a novel technology for food processing. It is an electrical resistance heating technique, in which heat is produced by electrical resistance of food materials. Electrical conductivity of food products should be greater than $0.05 \mathrm{~S} / \mathrm{m}$ for good behaviour of ohmic heating. Electrical conductivity of food products usually increases with temperature and water content.

Ohmic heating is rapid and uniform heating method. In this method electrical energy is converted into thermal energy. This method can be used in several sectors of food processing such as thawing process, blanching, sterilization, pasteurization, enzyme inactivation, expression, extraction, desalination and wastewater treatment, rice bran stabilization, and tofumaking process, semi meat ball cooking and drying process. It gives high and good quality products; it takes less cooking time and decrease microbial activities from the food and increases the shelf life of food products during storage period.

\section{References}

1. De Alwis A A P, direct resistance heating in the food industry. J Food Eng1990; 11:3-27.

2. Qihua T, Jindal V, Van Winden J. Compute Electron Agric. 1993;9:243-253.

3. Robberts J, Balaban M and Luzuriaga, D. Compute Electron Agric. 1998; 19:211-222

4. Marcotte M, Ram swami H and Piette G. Food Res Int. 2004; 31:493.502.

5. Sakr Mohamed, Liu Shuli. A comprehensive review on applications of ohmic heating $(\mathrm{OH})$. Renewable and Sustainable Energy Reviews. 2014; 39:262-269.

6. Zell M, Ling J G, Morgan D J, Cronin D A Ohmic heating of meats: Electrical conductivities of whole meats and processed meat ingredients. MeatScience. 2009; 83:563-570.

7. Assiry A M, Gaily M H, Alsamee M, Sarifudin A. Electrical conductivity of seawater during ohmic heating. Desalination. 2010; 260:9-17.

8. Goullieux A, Pain J P. Ohmic heating. 
InEmerging technologies for foodProcessing, Ed, Sun D W; ElsevierAcademic Press: USA. 2005; 469-505.

9. JaeYong Shim, Seung Hyun Lee, SoojinJun. Modeling of ohmic heating patterns ofmultiphase food products usingcomputational fluid dynamics codes.Journal of Food Engineering. 2010; 99:136-141.

10. Kumar J P, Ramanathan M, Ranganathan T V. Ohmic heating technology in food processing - A review. International journal of engineering research and technology.2014; 3:1236-1241.

11. Kim et al., Targeted genome editing in human cells with zinc finger nucleases constructed via modular assembly. Genome Research.1996; 19(7):1279-88.

12. Lebovka Nikolai et al., Does electroporation occur during the ohmic heating of food. Journal of food science. 2006; 70(5):308311.

13. Cho et al., Growth kinetics of lactobacillus acidophilus under ohmic heating. Biotechnology and Bioengineering. 1996; 49:334-340.

14. Srivastav Shivmurti, Roy Srishti. Changesin electrical conductivity of liquid foodsduring ohmic heating. Int $\mathrm{J}$ Agric \& BioEngg. 2014;7:133-138.

15. Lima et al., (1999a) The effects of ohmic heating frequency on hot-air drying rate and juice yield. J Food Science 41:115-119

16. McKenna B M, Lyng J, Brunton N, Shirsat $\mathrm{N}$ (2006) Advances in radiofrequency and ohmic heating of meats. J Food Eng 77:215229

17. Palaniappan S, Sastry S K. Electrical conductivities of selected solid foods during ohmic heating. Journal of Food Process
Engineering. 1991; 14:221-136.

18. Duygu Balpetek, Umit Gurbuz. Application of Ohmic heating system in meat thawing. Procedia-Social and behavioural Sciences.2015;195:2822-2828.

19. Sengun Yucel Iikin et al., Effects of ohmic heating for pre-cooking of meatballs on some quality and safety attributes. LWT- food science and technology. 2014;55:232-239.

20. Ito R, Fukuoka M, Sato N H. Meat Science.2014;96(2):675-681.

21.Zhong T, Lima M. Bioresource Technology. 2003;87(3):215-220.

22. Kim J, Pyun Y. Extraction of soy milk using ohmic heating. Abstract, Nineth Congress of Food Sci. and Tech, Budapest, Hungary; 1995.

23. Lima et al., Diffusion of beet dye during electrical and conventional heating at steadystate temperature. Journal of Food Process and Engineering.2001;24(5):331-340.

24. Allali H, Marchal L, Vorobiev E. Blanching of strawberries by ohmic heating: effects on the kinetics of mass transfer during osmotic dehydration. Food and Bioprocess Technology. 2008;3:406-414.

25. Sensoy I, Sastry S K. Journal of food science. 2004;69:7-13.

26. Ranmode Sarika, Manoj. Enhancement of juice recovery from carrotusing 2 stage pressing with ohmic heating. Journal of Engineering and technology. 2011;6(2):240251.

27. Dhingra Devinder, Chopra Sangeeta, Rai. Stabilization of raw rice bran using ohmic heating. Agric Res. 2012;1(4):392-398.

28. Stirling R (1998) Ohmic heating-a new process for the food industry. $\mathrm{J}$ food Eng 6:365-371.

\section{How to cite this article:}

Anjaly, M. G. and Ann Annie Shaju. 2021. Ohmic Heating Technology - A Review. Int.J.Curr.Microbiol.App.Sci. 10(12): 177-182. doi: https://doi.org/10.20546/ijcmas.2021.1012.020 